EPJ Web of Conferences 33, 01001 (2012)

DOI: 10.1051/epjconf/20123301001

(C) Owned by the authors, published by EDP Sciences, 2012

\title{
How a future energy world could look?
}

\author{
M. Ewert ${ }^{1}$ \\ ${ }^{1}$ E.ON AG, Technology \& Innovation, 40479 Düsseldorf, Germany
}

\begin{abstract}
The future energy system will change significantly within the next years as a result of the following Mega Trends: de-carbonization, urbanization, fast technology development, individualization, glocalization (globalization and localization) and changing demographics. Increasing fluctuating renewable production will change the role of non-renewable generation. Distributed energy from renewables and micro generation will change the direction of the energy flow in the electricity grids. Production will not follow demand but demand has to follow production. This future system is enabled by the fast technical development of information and communication technologies which will be present in the entire system.

In this paper the results of a comprehensive analysis with different scenarios is summarized. Tools were used like the analysis of policy trends in the European countries, modelling of the European power grid, modelling of the European power markets and the analysis of technology developments with cost reduction potentials. With these tools the interaction of the main actors in the energy markets like conventional generation and renewable generation, grid transport, electricity storage including new storage options from E-Mobility, Power to Gas, Compressed Air Energy storage and demand side management were considered. The potential application of technologies and investments in new energy technologies were analyzed within existing frameworks and markets as well as new business models in new markets with different frameworks.

In the paper the over all trend of this analysis is presented by describing a potential future energy world. This world represents only one of numerous options with comparable characteristics.
\end{abstract}

\section{Mega trends drive the change}

Future energy world change continues to be driven by Mega Trends which started to become increasingly important at the beginning of the 21 st century:

- De-carbonization to reduce climate change effect

- Globalization and localization / individualization to become more independent from large organizations and infrastructures, whilst also recognizing that the number of people living in cities are increasing

- Increasing role of information and communication technologies which has led to an optimization of millions of energy appliances and production units, due to low transaction costs, and further supports the trend to individualization 
Imagine the world of 2040 viewed through the lenses of today's known technologies, how might an energy system of the future look like, how would it function and what might be the role an energy company?

Due to already measurable effects and impact of climate change the need for change is accepted world wide. One reason is that for each tonne less of $\mathrm{CO}_{2}$ emitted there is a related reduction in cost. Costs related to each tonne of $\mathrm{CO}_{2}$ emitted are reflected by high $\mathrm{CO}_{2}$ certificates and $\mathrm{CO}_{2}$ taxes.

De-carbonization has led to binding worldwide measures and targets which, although differing from region to region in ambition, the overall direction is the same. For Europe, the target of $80 \%$ reduction by 2050 is now, in the year 2040, seen as achievable and well on the way to being reached.

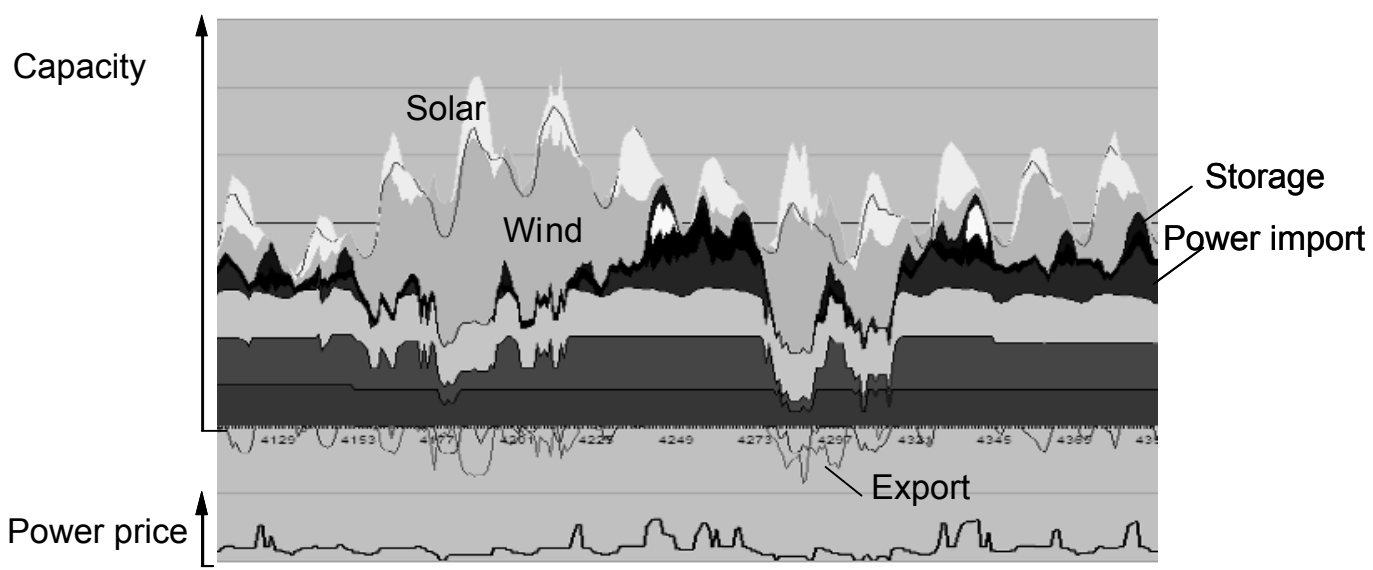

Fig. 1. Fluctuation of power generation by renewable technologies and structure of power prices in the transition phase to a future energy system for a time span of two weeks [1].

Due to the relatively low variable costs of the renewable generation the spread of power price is flattened during hours of high wind or solar production and price peaks occur in hours with low renewable production. The flattened price curves during days with high renewable production and peak prices when there is low power production from renewables creates an incentive to invest in storage, demand side management or grid infrastructure until sufficient flexibility is available in the market.

\section{Renewable energy substitute fossil energy}

As a result of the significant investments in renewable energy technologies, Europe continued with the installation of renewable generation on the level of 2010-2020 and has achieved already by 2040 $60 \%$ of the power production from renewable energy. The main technologies invested in are wind, biomass and solar, while the other less fluctuating technologies like marine or geothermal energy are achieving increasing shares. Emerging countries like China have installed 10 times more renewable power production than Europe.

At the same time the non renewable generation has reduced production and these assets have been adapted to a more flexible operating mode, mainly because not all the entire power demand on the system is flexible, so a small amount of flexible production is needed to follow the fluctuating production from the renewable energy coupled with the installed storage. 


\section{Power replaces other secondary energies}

Because the reduction of $\mathrm{CO}_{2}$ in the power sector was more easily achieved, compared with other industries and sectors, overall power production has continuously increased over the last two decades since 2020, even though usage of power has become more and more efficient. The technical potential of additional $\mathrm{CO}_{2}$ free power production is still high. For that reason energy appliances switched from fossil energy for e.g. heating and cooling to $\mathrm{CO}_{2}$ free renewable power as well as in the transport sector where cars moved from fossil based fuels to E-cars. Bio-fuels and bio-gas being used for heavy road transportation and air travel.

For Europe this transition and substitution has resulted in an overall $20 \%$ increase of power demand in the last decades.

\section{Energy demand de-coupled from fluctuating power production}

The key challenge for the 2040 European energy system, with $60 \%$ power production mainly from fluctuating renewable energy, is stability of the system and shaping demand to meet the production. To handle the fluctuations a set of different measures have been applied. To transport power from large renewable generation locations to centers of demand, new direct current lines and cables were built. This provides the most efficient way to transport power and keep the system stable.

When the power production is not backed by demand, the excess power is used to produce hydrogen close to the wind park and the hydrogen fed into the gas infrastructure. A large transport gas pipeline at the coast can integrate long-term $1.5 \mathrm{GW}$ excess wind power production by feeding up to $15 \%$ Hydrogen into the pipeline. In the main, the use of energy follows the production from renewables, with the demand being fluctuated according to the production from renewables by shifting the loading of batteries for E-Cars, producing heat with heat pumps which is stored in hot water tanks, or using purpose build storage devices integrated local to high demand centers. Industries shift their energy demand automatically whenever possible and are rewarded by flexible real time tariffs, this includes increasing the use of their own local thin-film PV renewable source to receive additional tariff reward if they avoid grid.

When there is a lack of renewable power production, the stored electricity from pump hydro, batteries or compressed air energy storages at the coast lines is used. Thermal energy from heat/cryogenic storages produced earlier at a time when there was excess power production is used to heat or cool the building or the neighboring building without need for power or fuel. Small distributed units, such as gas engines or fuel cells in households are used to produce backup power in these situations. They operate and produce heating or cooling energy for the buildings increase efficiency of the gas power production. To some extent they are using the hydrogen produced with wind power some hours or weeks before. If there is no heat demand the units operate in a power production only mode. A small number of large flexible power plants ensure system stability and cover the residual demand in generation capacity which can not be time shifted or delivered by low carbon systems (central and distributed) with low variable costs.

\section{Communication is the key element to manage the millions of devices}

The backbone of this future energy system is the infrastructure for information and communication technology installed in all single elements of the system (power, gas, heat, cooling energy) including households, offices and industrial premises.

There is no centralized data storage of all single appliances or production units, this is not necessary. Instead optimization takes place in a network based on distributed intelligence / agents. Households are automatically optimizing their energy production units and energy appliances internally, receiving information about current and future weather conditions, power prices at the 
energy exchange and loads in the adjacent grid. With this information they optimize their building or production line, each household, commercial or industrial user is an active producer, consumer and trader. Of cause this optimization of comfort, convenience and cost takes place in the background without the need for active controlling by house owners, office users or industrial companies.

Energy companies provide energy service solutions, tools and applications to their customers so they can customize and optimize their own energy demand, distributed energy production and also efficient heating and cooling systems, E-cars and renewable production devices. These tools and applications manage this household system, supplemented by appliance maintenance service providers. Energy companies also deliver renewable or low $\mathrm{CO}_{2}$ energy for cities, where the city is not able to produce sufficient energy based on renewable sources in the city area and have to import energy. Energy companies combine the energy optimization with other services for building energy management, heating, cooling, energy analysis and recommendations for refurbishments, and related energy and building management services.. The business relies on large and small assets as well as the intelligent bundling of small and large devices to make the system work.

\section{Characteristics of the future energy world}

The future energy world will be characterized by new key elements compared to the very deterministic energy system of the past. In the past system, the energy was produced by dispatcheable generation units and the quantity and timing of electricity demand was well known in advance. In the same respect transportation of the energy from central generation through the grids to the consumers was predictable with very high accuracy of some percent of the load for more or less the entire year in advance.

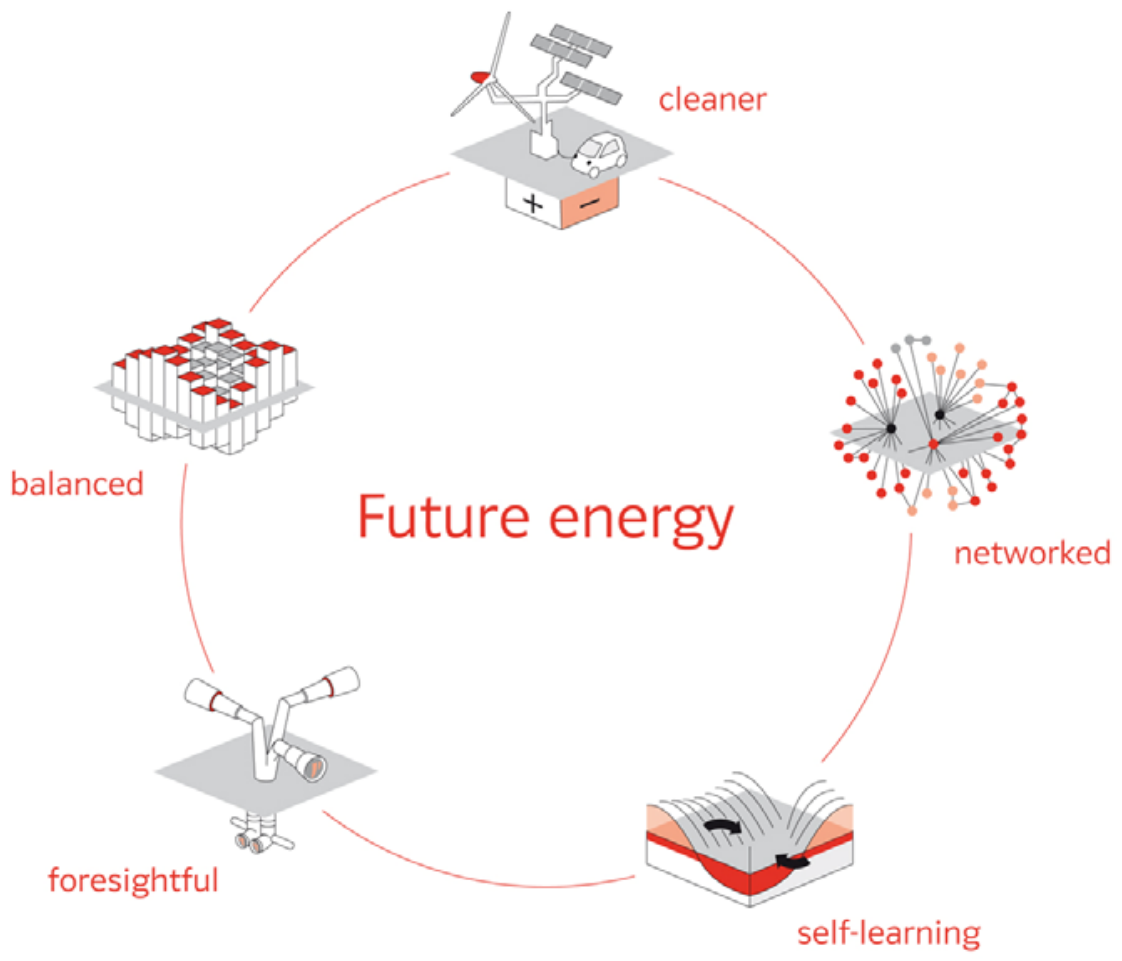

Fig. 2. Key characteristics of the future energy system. 
The future system is characterized by five key elements which are:

- 'cleaner': Low $\mathrm{CO}_{2}$ emissions and fossil energy demand which results in a high share of renewable generation.

- 'balanced': All distributed elements of the system contribute to the balancing of the system be it in the high, medium or low voltage grid and even the heating, cooling and gas infrastructures will contribute to this balancing. On the other hand the energy should be affordable for the customer.

- 'networked': All components will be interlinked by information and communication technologies, customers and energy companies use information within the system, which is an internet of things

- 'foresightful': Operation of appliances, generation devices and storages will be controlled according to future weather forecasts, so that the demand will be actively shifted to times with high renewable production

- 'self-learning': Players automatically reacting on changing behaviours within the system which can occur from additional power lines, storages or increasing renewable production. These changes will have an influence on all the elements of the system

\section{Transition from todays to the future system}

For a successful transition from today to a future energy system four main developments have to happen:

- Technology developments and commercialization

- New frameworks to create business cases

- Markets with high investments in new technologies

- Public acceptance

Many technologies described in the view of a future energy world are already known and commercially available. Some technologies are known and available as pilot applications but have to become commercial products with significant cost reductions compared to today. These are for example compressed air energy storages, batteries, E-vehicles, smart grid components, smart appliances in households, platforms to interlink the appliances and intelligent agents to control the sub-system in a household or office building. Therefore investments in development and commercial production lines have to be made. These investments mainly depend on the attractiveness of the expected markets.

Even if technologies are available and their application is adding value to the system from an overall economic perspective, they will not be applied if there is not an appropriate framework to create businesses cases and initiate investments. For example the use of car batteries to store electricity and feed it into the system later is very cost effective from an overall economic perspective. However even if there are millions of E-vehicles which are prepared to support the energy system they will not do so under current framework conditions. Even if the power price at the power exchange is very low and close to $0 € / \mathrm{MWh}$, households have to pay for grid fee, taxes and other costs. This leads currently to a power price for loading the battery of around $180 € / \mathrm{MWh}$ in Germany. If the power is fed into the grid and revenues are received according to the actual wholesale power prices, in that case there is no business case for storing energy under the current framework. To unlock the business case, the charging energy would need to be released from costs like grid fees, taxes or other non energy related components.

To achieve the system benefits from new components a significant number of new devices is required. For example for a relevant impact of demand side management in households many heat pumps and E-vehicles are necessary or many batteries for distributed storage of power from PV modules, making the energy more dispatchable. In a similar way new micro Combined Heat and Power units for local power production could be used to back-up the downstream system in time of low renewable feed-in. 


\section{EPJ Web of Conferences}

Public acceptance is a critical precondition for many investments. Additional infrastructure investments in transport or distribution grids are one example. The future energy system will look very different from that described here if there is no acceptance for investments in power lines and no acceptance for continued investments in onshore wind parks close to the customer. The willingness of consumers to become part of the energy system or in other words become prosumers is also a key element for the portfolio of the future energy system.

\section{Summary}

The future energy system, with a significant share of fluctuating renewable generation, needs flexibility which can be provided by gas power plants, grid extension, storage and demand side management. The impact of fluctuating generation on energy prices needs to provide price incentives for investments in these technologies. For the transition of the system from today to a future system with many distributed applications the information and communication technologies are key enabling technologies.

To realize the change in an efficient way the commercialization of the enabling information technologies, software platforms and applications have to be realized. In many cases and in particular with distributed applications this new operating environment will bring new challenges, new business models and new opportunities, supported by appropriate market and policy framework. In order to understand the interactions between the different elements of such a complex system new integrated simulation tools are essential to combine the power, heating, cooling and gas systems and to analyze the alternative frameworks which could be introduced to design a competitive market driven approach.

\section{References}

[1] Internal calculations (2011) 